\title{
Autonomous Fire Fighting Robot with Smart Monitoring System
}

Nurain Izzati Shuhaimi, Mohammad limam Shafiq, Ezmin Abdullah, Norhafizah Burham, Rafidah Rosman and Suzanna Ridzuan Aw

To Link this Article: http://dx.doi.org/10.6007/IJARBSS/v11-i12/11983

DOI:10.6007/IJARBSS/v11-i12/11983

Received: 19 October 2021, Revised: 22 November 2021, Accepted: 12 December 2021

Published Online: 25 December 2021

In-Text Citation: (Shuhaimi et al., 2021)

To Cite this Article: Shuhaimi, N. I., Shafiq, M. I., Abdullah, E., Burham, N., Rosman, R., \& Aw, S. R. (2021). Autonomous Fire Fighting Robot with Smart Monitoring System. International Journal of Academic Research in Business and Social Sciences, 11(12), 2525-2537.

Copyright: (C) 2021 The Author(s)

Published by Human Resource Management Academic Research Society (www.hrmars.com) This article is published under the Creative Commons Attribution (CC BY 4.0) license. Anyone may reproduce, distribute, translate and create derivative works of this article (for both commercial and non0-commercial purposes), subject to full attribution to the original publication and authors. The full terms of this license may be seen at: http://creativecommons.org/licences/by/4.0/legalcode

Vol. 11, No. 12, 2021, Pg. 2525- 2537

Full Terms \& Conditions of access and use can be found at http://hrmars.com/index.php/pages/detail/publication-ethics 


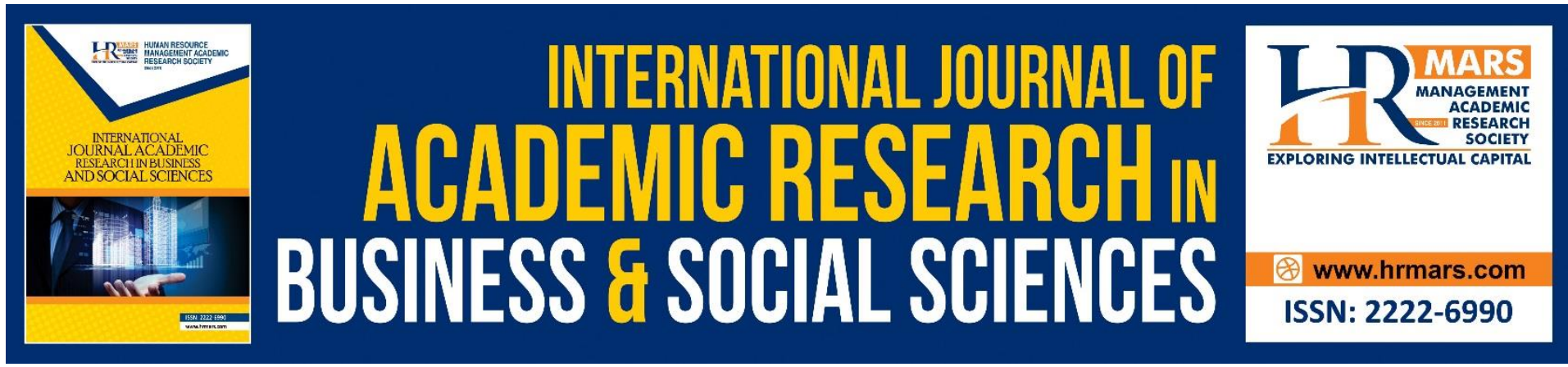

\title{
Autonomous Fire Fighting Robot with Smart Monitoring System
}

\author{
Nurain Izzati Shuhaimi ${ }^{1}$, Mohammad limam Shafiq ${ }^{2}$, Ezmin \\ Abdullah $^{3}$, Norhafizah Burham ${ }^{4}$, Rafidah Rosman ${ }^{5}$ and \\ Suzanna Ridzuan Aw6 \\ 1,2,3,4,5Faculty of Electrical Engineering, Universiti Teknologi MARA Shah Alam, \\ 40450 Shah Alam, Selangor, MALAYSIA, ${ }^{6}$ University College TATI (UCTATI), Telok Kalong, \\ 24000 Kemaman, Terengganu, MALAYSIA.
}

\begin{abstract}
The fire incident is one of the man-made disasters in Malaysia due to the frequency of reported fire cases recently. The majority of all cases that involved domestic buildings had very catastrophic effects such as property losses, permanent disability to the victim, and death. We are all aware of how fast fire can spread when it rages. Therefore, owners have to be alert at all times to any factor that might lead to any small fire and that is not possible to achieve. As humans, we might get distracted by other surrounding activities but not for robots. Thus, a Fire Fighting Robot has been developed and was controlled by Arduino Uno. It is designed in a smaller size in order to ease small location entry, fully equipped with high sensitivity sensors to achieve the required research objectives of searching, detecting, and extinguishing the fire. The combination of ultrasonic and flame sensors creates a perfect guide for the robot to work effectively. This autonomous robot will search and locate the fire and send a notification to the user through Blynk application; before the extinguishing process occurs. Blynk application will also provide a monitoring platform for the user to receive information including live streaming and flame data. We tested the performance of the robot by varying the distance and size of fire source to the robot. The graph trend line showed that the time taken was linearly proportional to the distance and size of fire. We managed to obtain the equation of the dependent variable from simple linear regression. From the $R^{2}$ value of 0.9888 and 0.9865 , we can say that it has a strong relationship between both variables. To summarize, the experimental result has proved its capabilities as a reliable fire protection system by searching and extinguishing a fire in time.
\end{abstract}

Keywords: Man-Made Disaster, Autonomous Robot, Arduino Uno, Blynk Application and Fire Protection System.

\section{Introduction}

Firefighting is a very dangerous and high-risk job in saving human life. A fire-fighter has to be alert and well prepared at any time so that they are able to reach the fire in a short time and safely extinguish the fire. The quick action by them can prevent further damage and reduce fatalities of a burning area (Wang et al., 2011). A house is a place for shelter, and certainly not 
a place where a person has tragically been taken away from his life. With the advanced technology, the gap between firefighting and machines have been finally bridged allowing for a more effective and operative method of fire extinguishing (Xin et al., 2018).

Over the years, fire cases in Malaysia from all aspects have grown rapidly. Majority of all the cases that involved domestic buildings had very catastrophic effect such as assets losses, serious injuries to fire victims, and death (Woodrow, 2010; Ramsay et al., 2018). Moreover, according to the Director-General of Fire and Rescue Department Malaysia, about 6,000 premises are destroyed by fire every year with 40 percent of these involve private houses (Muhamading, 2016). The increase of death counted due to fire accidents mainly in residential buildings is enough to trigger us to be aware not only of robbery but also on fire safety. The contribution to the causes of fire in the household includes cooking, smoking, and candles (Ahrens, 2018; Kobes, 2017; Ahrens, 2017a).

Therefore, the main purpose of this project is to contribute to the growth of automation systems by developing an automatic fire extinguisher robot. The robot is to protect human life, wealth, and environment from fire accidents. This is very crucial whenever unexpected fire accident occurs while people who live in the house is either sleeping or not present in the house. The robot will not only help in detecting fire but also notify the user so that they will be prepared with another alternative such as calling the firemen. Fire spread is very fast and it doubled every minute (Wrack, 2010). This eventually will lead to the forming of smoke rapidly causing to why most victims cannot survive. Hence, the initial detection of fire plays an important role since it gives a higher chance of survival.

\section{Background of Study}

Fire is a phenomenon of burning expressed in light, flame, and heat. It is a process in which substances chemically combine with oxygen and fuel, which generally gives an output of lively light, heat, and smoke (Pyne, 2016). During the fire situation, in order to stop the gas supply to the fire, one solution can be done which is fuel surface temperature must be lowered. To ensure this, direct extinguishment where direct water is aimed at the base of fire would give more chance in putting out the fire as water will evaporate and energy from the fuel itself will be extracted (Lambert, 2013). This results in a temperature drop.

\section{Fire Extinguisher}

It is one of the active fire protection devices. It is convenient, portable equipment by directing the nozzle to the fire to extinguish a small fire but not fighting a large or spreading fires (Lyman, 2018). The method requires the user to manually take full control during extinguishing fire. When the user has the knowledge to use the fire extinguisher properly, it can save lives and property because this equipment can control the fire rage until the fire unit arrives for further extinguish process (Kodur et al., 2019). Extinguishers are very sensitive because they need to be checked regularly and require routine care to make sure the content inside is still in perfect condition.

\section{Sprinkler System}

An automatic fire sprinkler system is another fire protection that is created with sensors for it to be activated when sensing any fire in the optimum distance. It is normally mounted to the ceiling at a high place for a better sensing area. Sprinklers are the best option from its reliable outputs for any buildings' fire protection. They rely on steady water supply and extinguish any fires that ignite around them (Ahmed et al., 2015). However, there is still 
inconsistency in sprinkler where the system fails to be activated when there is fire (Abdelghany, 2019). The reason for that is, it may not activate because the heat from a fire is still not enough to trigger the heat sensor in the sprinkler. Nevertheless, a $100 \%$ effective sprinkler system is still not assuming a whole reduction in loss. In order for sprinklers to activate, it must reach a certain level of temperature and by the time it does, the fire size has already been out of control and destroy many valuable things (Frank et al., 2013). In the fire situation, it is tested that half of the sprinkler's ineffectiveness is due to water does not reach fire (Ahrens, 2017b)

\section{Smoke Detector}

A smoke detector functioning as a detector where a fire is sensed through smoke sensing. The difference between each type of detector is the way they sense fire. This model is the best choice at detecting smoky fires that start with smoke before finally breaking into flames. They have proven much more effective in detecting fires in residential homes. If we occupied them, we still have to take care by checking the batteries (Warmack et al., 2012). The popularity of smoke detector gives a big impact to the fall in fire deaths over 40 years. According to the National Fire Protection Association (NFPA) in the United States, the fire death rate is over twice as high in homes that have a problem of working smoke alarm or no alarm at all. It is recorded among the houses having a smoke alarm, $43 \%$ of the fire cases are where it is failed to give alarm sound, not functioning, and missing batteries (Ahrens, 2019). Hence, checking the alarm works or not is very important because we cannot predict any unwanted cases (Moinuddin et al., 2017).

\section{Comparison}

The main reason for this proposed work is to provide an automatic fire-extinguishing system which eliminates the other pre-described disadvantages. While fire alarm systems are designed to provide warning against fire, they still do not guarantee warning or protection. Noted that the fire extinguisher needs manpower to put out the fire which depending on user sensitivity. Hence, the user may take a longer time to extinguish fire since it depends on them. If the user is not around the residence, surely this will lead to complete loss. In solving this overlooked problem, a robot equipped with three high sensitivity temperature sensors is designed to search for a small fire. This robot can work continuously for 24 hours in searching for the fire which is more productive and consistent. From early prevention, we can avoid unwanted accidents.

Despite that, the work proposed by (Ahrens, 2017b) is less reliable then handling the small fire. This is because the liquid in the bulb of sprinkler will heat up and explode when only the temperature reaches 155 to 165 degrees Celsius, then only it triggers the release of water. Thus, it only triggers as it reaches a certain point of temperature were at that time the fire can probably rage and spread rapidly. At the moment surely it does have consequences to the building area. The method does extinguish the fire at an optimum time but the building may not be as its initial condition. To overcome this, a firefighting robot will be developed and try to search for any small fire to extinguish before it rages. Besides, it can avoid loss of cost suffered in the event of a fire.

Besides, the work described by (Warmack et al., 2012) cannot be expected to sense fires due to several reasons. The amount of smoke present may be insufficient to alarm smoke detectors because smoke occurs when there is incomplete combustion. That means at the point heavy smoke occurs, there is not enough oxygen present. To overcome this unwanted 
situation, the robot which moves at every corner of the house will surely detect small fire. It is very sensitive to dust particles and insects, meaning that regular maintenance is needed which is the opposite of the robot where it only needs to make sure its battery life at full power. Furthermore, the smoke alarm should be tested weekly to make sure all sensors and transmitters are working properly which is going to be a burden (NEMA, 2017).

\section{Methodology}

The development of the Fire Fighting Robot can be described in several parts such as prototype design, hardware design, and robot flowchart. This section will be discussed in detail on all the components used in this project including hardware and software. These two relate to each other in constructing this robot mechanism.

\section{Prototype Design}

Fig. 1 shows the final prototype of the robot. The robot has a strong acrylic base to hold all the electronic components steadily. It is facilitated by the two gear motors and one caster wheel. The robot is stable during the operation and capable of rotating up to 360 degrees with no problem. For the body structure of the robot, we equipped with lightweight and soft pine wood. Moreover, the specialty that pine wood offers is the ability to stand temperature up to 250 degrees before it ignites (Tsoumis, 1991). Thus, the robot can move at great speed with high endurance. Other mechanical parts including hose stand, servo stand, sensor guard, and camera enclosure make the robot firmer hold the component. The position of the ultrasonic sensor and flame sensors are at the front of the robot to obtain an accurate result for the system. Besides, the guard is installed to protect the flame sensors to strike any near obstacles while operating the process. Additionally, the camera OV2640 is installed at the front side to capture the whole situation during the process and stream directly to the user smartphone.
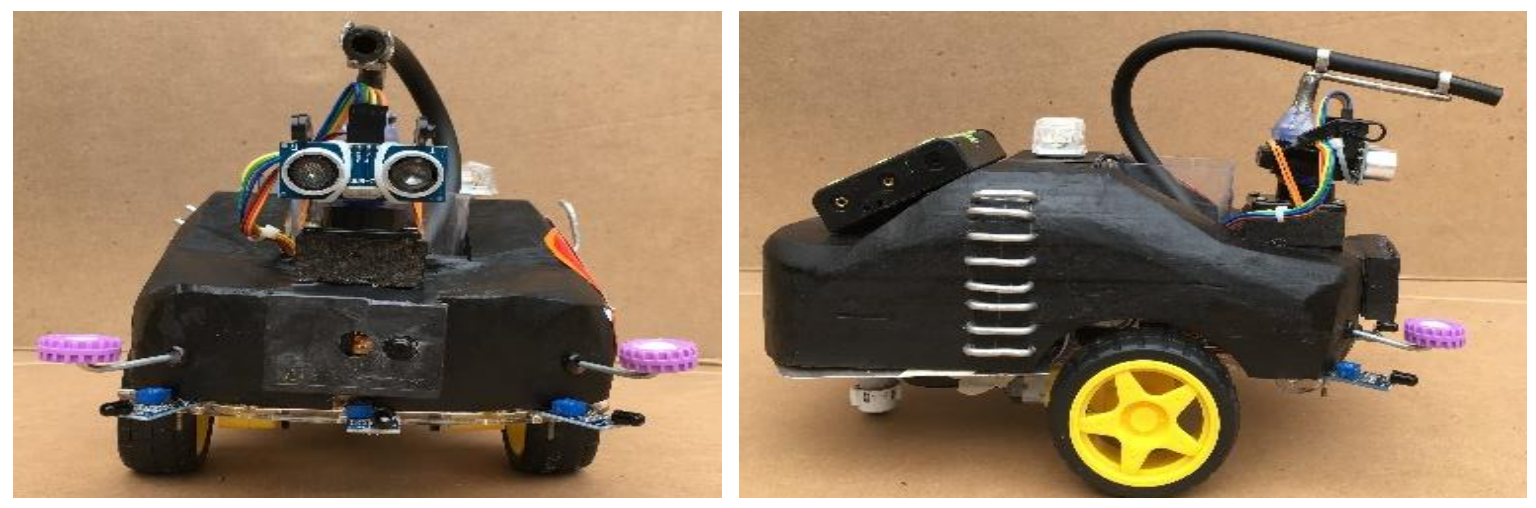

Fig. 1: Final prototype of Fire Fighting Robot.

\section{Hardware Design}

From the block diagram in Fig. 2, it shows the proposed work of Fire Fighting Robot which consists of a power supply, Arduino Uno R3, flame sensors, DC motors, ultrasonic sensor, servo motor, camera, Wi-Fi module and water pump. A regulated supply of $11 \mathrm{~V} \mathrm{DC}$ has been provided from the power supply unit in order to power this circuit. 


\section{Arduino Uno R3}

Arduino Uno controls all the actions and commands of this project. All the digital and analog input and output pins are connected to the microcontroller board. Thus, the use of Arduino is simpler and straight forward as it can be compatible with any computer.

\section{Infrared Flame Sensor}

IR based flame sensor has chosen since it has all the capabilities to detect fire (Prasojo, I. et al. 2020). Analog pins are used to detect the exact wavelength of a different light. The sensor can give high sensitivity to the flame spectrum with a wavelength varied between $700 \mathrm{~nm}$ to $1000 \mathrm{~nm}$. We have increased our sensitivity to detect fire by using three flame sensors where the angle is about 60 degrees each.

\section{Ultrasonic Sensor}

Ultrasonic sensor will help the robot movement to avoid any collision with an obstacle that blocks the way. Since we will not be assisting the robot during the process and put full trust in the robot, the obstacle avoidance system is a compulsory feature. The transmitter sends a high-frequency sound signal at every time ranging from $2 \mathrm{~cm}$ to $400 \mathrm{~cm}$. When an object is found, the signal will reflect back and the receiver will receive it. The time calculated in between the process of transmission and reception can determine the actual distance to that object with known velocity in air.

DC Motor with Motor Driver

During the detection of fire presence, two 6V DC motors are used to move near the fire through the motor driver $\mathrm{L} 298 \mathrm{~N}$ module. It can control both speed and spinning direction of two DC motors making it ideal for building a two-wheel robot (Khechiba, 2016). The two geared rotating wheels of the robot will facilitate the movement of the robot.

\section{Servo Motor}

This motor attached to the spray nozzle for rotating it back and forth, from right to left during extinguishing the fire and object avoidance. It gives an important role so that the area of the fire is fully covered by spraying water to the area. The standard rotation servo can rotate $180^{\circ}$ with precision like the stepper motors which we will use in our robot.

\section{Water Pump}

The $5 \mathrm{~V}$ water pump works using the water suction method which drains the water through its inlet and released it through the outlet (Charkhawala et al., 2020). This will be submerged in the tank full of water to provide enough pressure. When the supply is $\mathrm{ON}$, the water will be suck at the inlet part and flow out of the outlet through the pipe. 
ESP32 Cam with OV2640

In order to provide more security to the proposed work, a camera is installed on top of the robot to capture and give live recording before, during, and after the fire extinguishing process. It will live streaming to the user smartphone by Blynk application through the Wi-Fi module.

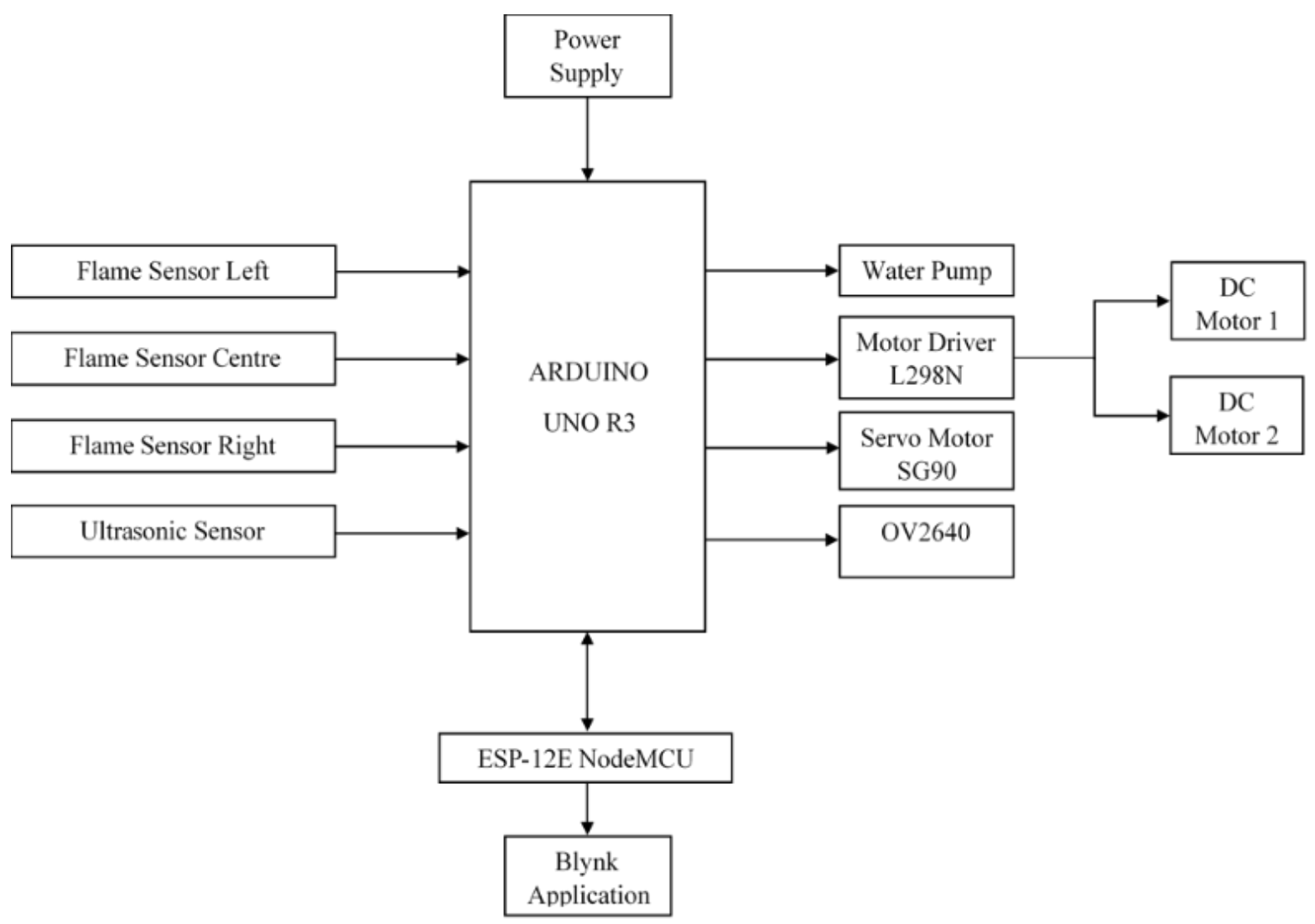

Fig. 2: Block diagram of Fire Fighting Robot.

\section{System Flowchart}

Fig. 3 shows the operation of the Fire Fighting Robot which depends on the user when they want to operate it. As the user switches ON, the robot will start with DC motor 1 and 2 simultaneously operate by rotating the wheels to move. In order to give extra security, the camera also functioning as the switch is ON. It will directly live stream to the Blynk application. The motors will keep rotating to search for any infrared light which is fire. At the same time, as the ultrasonic sensor detects any presence of an obstacle in front of the robot, it will rotate left or right depends on the condition to avoid any collision to the robot. Hence, the flame and ultrasonic sensors will work together to keep the DC motors updated. 

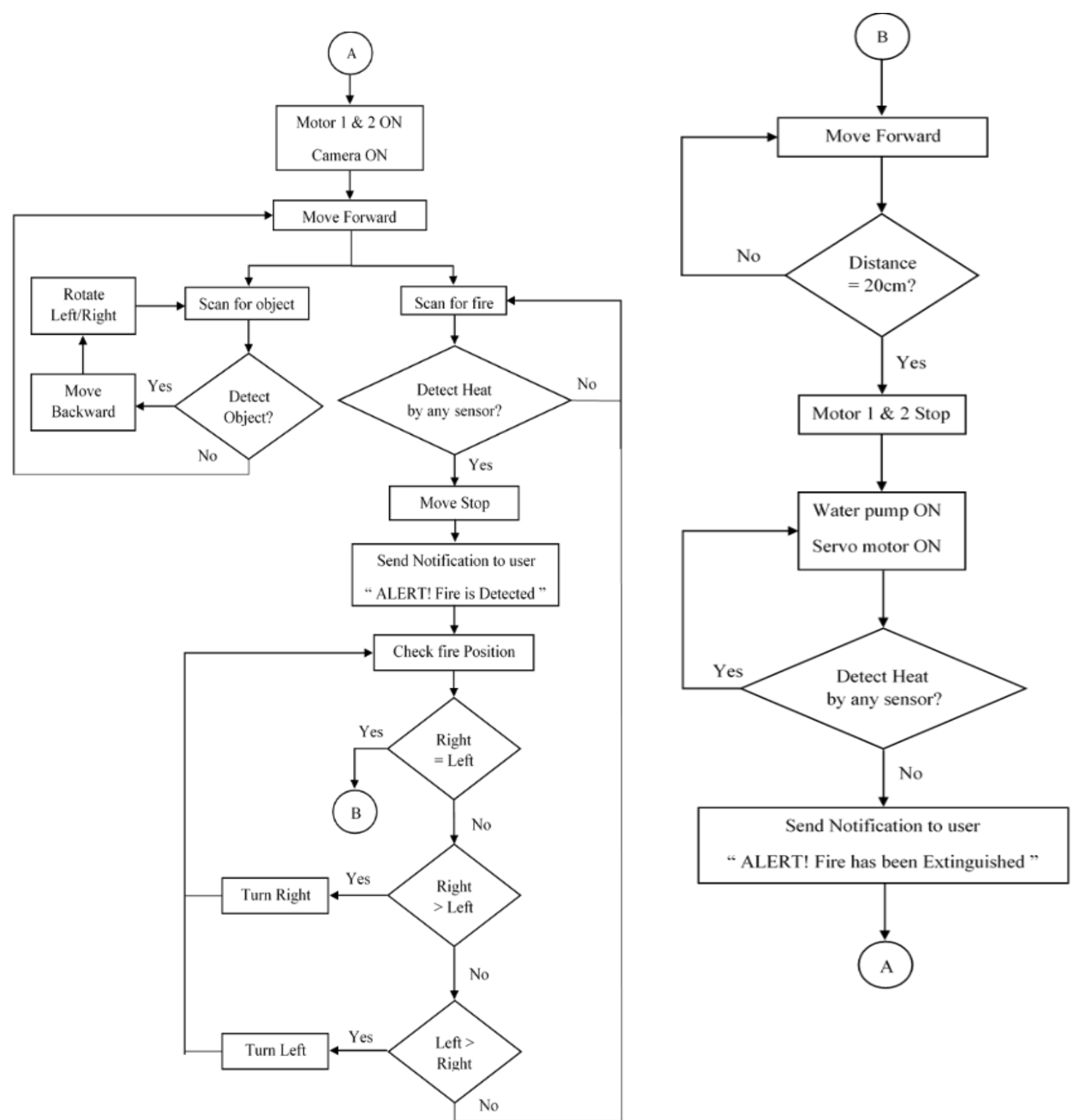

Fig. 3: Flowchart of the Fire Fighting Robot

If one of the flame sensors detects a fire, firstly it will send an alert message to the user to notify them that there is a fire in the house through their smartphone. After that, it will start to search the accurate position of the fire from information given by those three flame sensors. If the flame sensor on the right detects a certain amount of infrared light, the robot will rotate to the right to ensure that the fire always in line with it. The same process if the left sensor detects the infrared light. The robot is adjusted until the fire is in front of the robot and move to the second section, $B$.

In section $B$, the robot will measure the distance between the fires and will move forward until it obtains the optimum distance which is $20 \mathrm{~cm}$ before extinguishing it. If yes, DC motor 1 and 2 will automatically stop and the extinguishing process starts. The water tank equipped with sufficient water and a motor pump will give enough pressure to pump the water out. 
Water will flow out through a rubber tube as a spray system and servo motor will help in maximizing the covered area. The water pump and servo motor will work together and put out the fire until no heat is detected by the flame sensor. After finished, another alert message is sent so that the user to keep him or her updated to the current situation. Users can still observe the recording from the camera to check the causes of the fire. Finally, the robot will back to section $A$, which is searching the fire again.

\section{Result and Discussion}

To measure the performance of the robot, we tabulated a few data. First, we varied the distance of the robot from fire. We used a fire starter as a fire source. Next, we also analysed when the fire is double up at a fixed distance. Thus, we measured the time taken by the robot to detect the fire and extinguish it. Here, we can analyse the effectiveness of this smart fire protection. Note that the route that we used to examine the robot performance consists of three turns before reaching to fire.

\section{Ability to Extinguish Fire at Varied Distance}

Firstly, we tested the performance of the robot by varying the distance of the fire source to the robot. We prepared ten different distances starting from 0.5 meters to 5 meters. To ensure a more accurate result, we repeated the experimental process three times and calculated the average of each distance. Fig. 4 shows the graph of average time taken to extinguish a fire which depends on the distance to the fire.

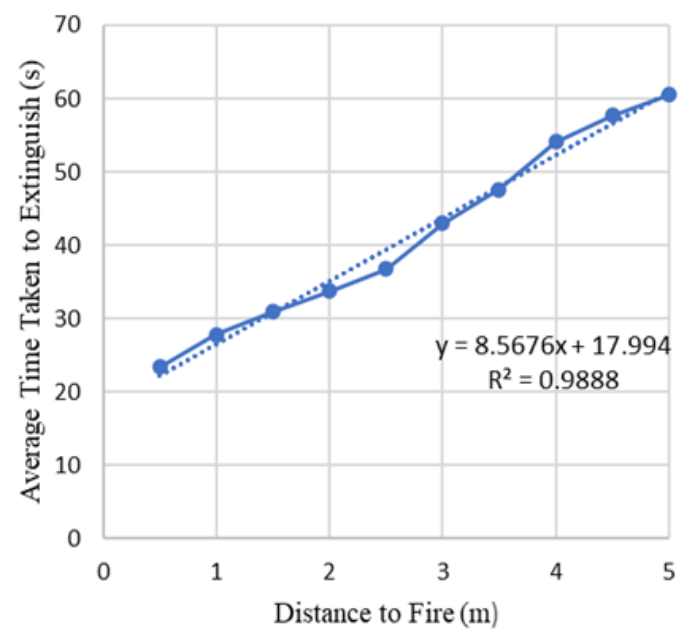

Fig. 4: Average time taken to extinguish fire with varied distance

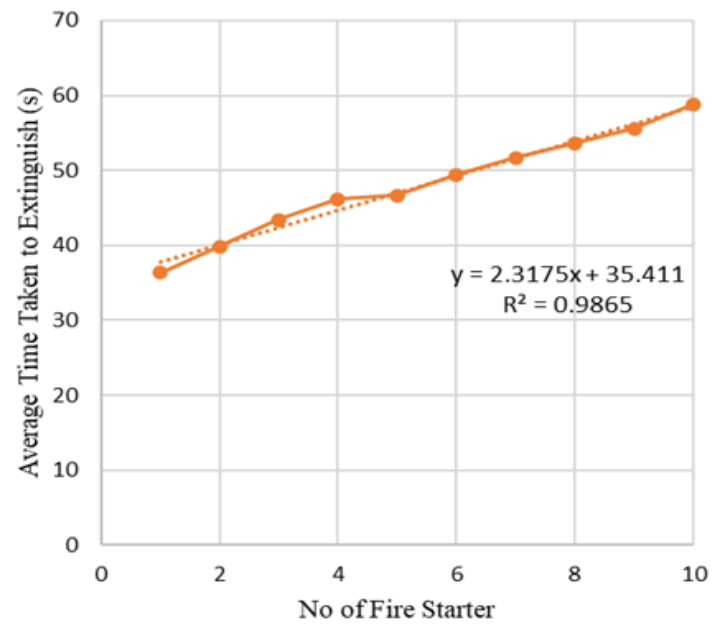

Fig. 5: Average time taken to extinguish fire with varied size of fire

During the experiment, we fixed the size of fire which we only used one fire starter. Thus, we can focus on the fire distance variable. From our observation, the robot took only 60.49 seconds to extinguish a fire at a distance of 5 meters while 23.38 seconds for 0.5 metre. The graph trend line showed that the time taken was linearly proportional to the distance of fire. We managed to obtain the equation of the dependent variable from simple linear regression. From the $\mathrm{R}^{2}$ value of 0.9888 , we can say that it has a strong relationship between the variables.

Hence, we can conclude that the further the robot distance to the fire, the longer the time taken it took to extinguish the fire. This variable is very crucial since practically we cannot 
expect where the fire would be. Hence, the ability of the robot to automatically search and extinguish the fire in a short time could be a lifesaver.

\section{Ability to Extinguish Fire at Varied Size of Fire}

We also analysed the performance of the robot by varying the size of the fire. This indicates how fast it can extinguish fire according to the variable. During the process, we tested ten sets with different sizes of fire by increasing the amount of fire starter from 1 piece to 10 pieces. The same process was repeated three times for more accurate results. We fixed the distance of the robot to the fire at only 2.5 meters so that we can only examine the fire size factor.

Fig. 5 shows the graph of average time taken to extinguish a fire which depends on the size of the fire. Our observation found out that there was a difference of 22 seconds to extinguish fire between 1 piece and 10 pieces of fire starters. Moreover, it took less than 1 minute to extinguish 10 fire starter which is a top-notch performance. The graph also showed that the time taken was linearly proportional to the size of the fire. From the $\mathrm{R}^{2}$ value which is 0.9865 , we can say that it has a strong relationship between the two variables.

Thus, we can conclude that the bigger the size of the fire, the longer the time taken it took to extinguish it. Fire size depends on what material it started to burn. Fire may rage out of control if it is not extinguished in optimum time. Therefore, the efficiency of the robot plays an important role to quickly put off the fire.

\section{Blynk Application}

We prepared a smart monitoring system where the user could easily monitor in case of fire situation to occur at any time. Fig. 6 shows result from the flame sensor where during fire detection, the value drops from 1024 to 0 . This data runs continuously as long as the robot is working and it can be reviewed by multiple timelines. Moreover, the application includes notification so that the user can be notified if there is a fire in their houses. Thus, users can prepare further action in case of fire rage. This notification alerts them during the early detection of fire.

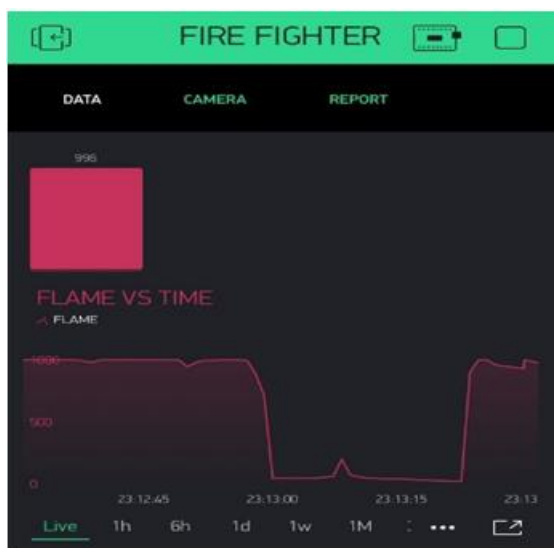

Fig. 6: Live data from flame sensor before and after fire extinguishment.

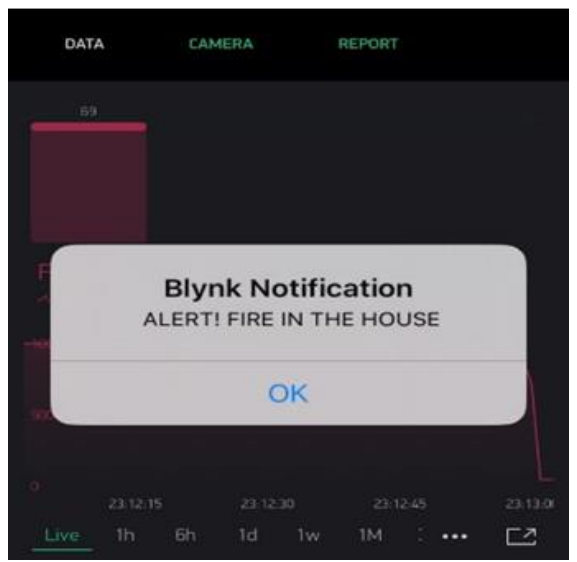

Fig. 7: Notification for user during fire detection. 


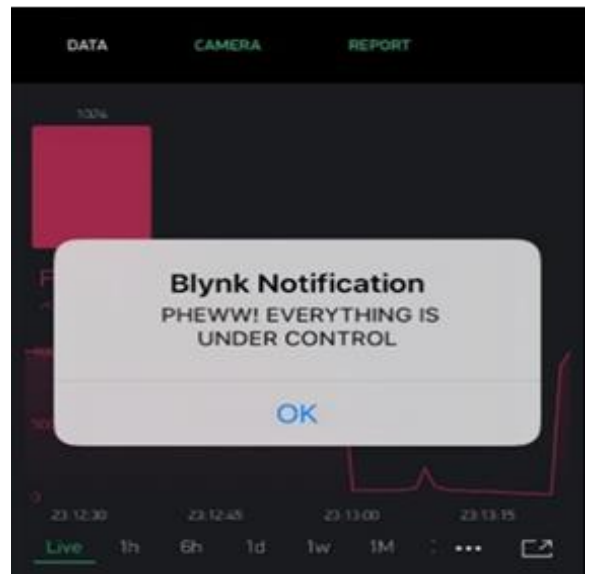

Fig. 8: Notification for user after fire detection.

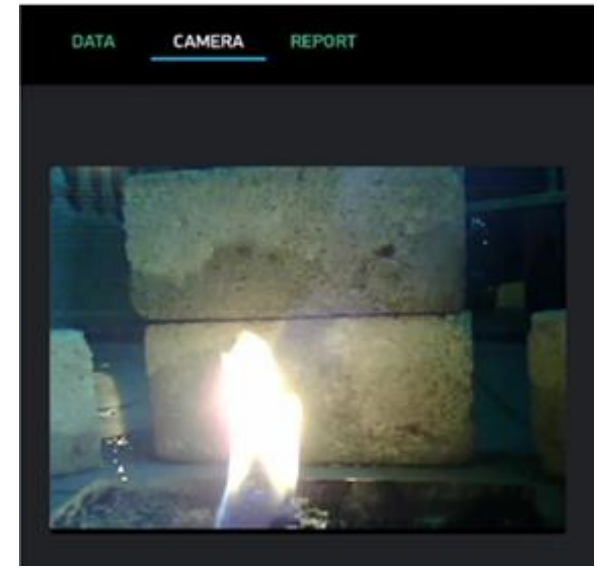

Fig. 9: Live streaming during fire detection.

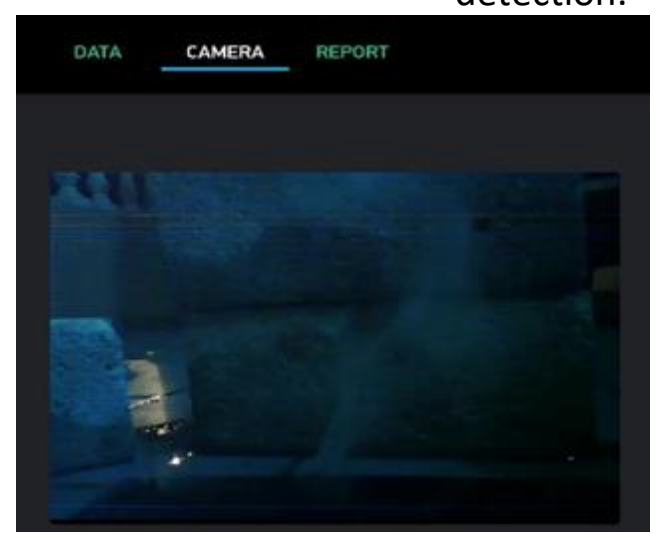

Fig. 10: Live streaming after fire extinguishment.

Fig 7 and Fig. 8 respectively show notification received during fire detection and after the fire has been successfully extinguished. Finally, a camera for the live streaming feature completes the security of the robot. Hence, the user able to check the fire status and the possible causes of fire. Fig. 9 and Fig. 10 show live streaming during fire detection and after the fire has been successfully extinguished, respectively.

\section{Conclusion}

In a nutshell, the project aims to provide security of home and building which is important to human life. Fire causes tremendous damage and losses of human life and property. There are many possibilities a fire can start in any household and the consequences may affect our life. We develop an intelligent multisensory based security system that contains autonomous firefighting system. The features that are available consist of object avoidance and fire extinguishment with smart monitoring using a smartphone makes it a more secure system. The Fire Fighting Robot has proved its performance and ability to extinguish a fire by varying distances of the robot to fire and the sizes of fire. The result showed that the range of time is acceptable and comparable to human sensitivity. The time factor is always being the indicator of this type of accident. The longer it takes to react; the worst the accident can happen. However, we have a few recommendations for future improvement that can advance the robot performance. First, a higher number of the flame sensor may increase the sensitivity to the fire since they will cover most of the area with less movement. Furthermore, a Wi-Fi 
controlled feature could improve its security because the user can control the movement of the robot whenever they want.

\section{References}

Abdelghany, S. (2019). The Benefit of Residential Fire Sprinkler Systems. 2-4.

Ahmed, A., Mansor, A., \& Albagul, A. (2015). Design and Fabrication of an Automatic Sprinkler Fire Fighting System. Lecture Notes in Control and Information Sciences. 789. 42-45.

Ahrens, M. (2017a). Home Candle Fires. National Fire Protection Association, NFPA.

Ahrens, M. (2017b). U.S. Experience with Sprinklers. National Fire Protection Association, (NFPA). 5-6.

Ahrens, M. (2018). Home Cooking Fires. National Fire Protection Association Research, (NFPA). 3-8.

Ahrens, M. (2019). Smoke Alarms in U.S. Home Fires. National Fire Protection Association (NFPA).

Charkhawala, A., Kajal, S.K., Kalyani, S., Pallavi, G.K. \& Vaishali, R.K. (2020). Solar Operated Purifired Water ATM using RFID Based for Rural Areas. International Journal of Innovative Research in Technology. 7, 1, 385-390.

Frank, K., Gravestock, N., Spearpoint, M., \& Fleischmann, C. (2013). A review of sprinkler system effectiveness studies, Fire Science Reviews. 2(1).

Kamel, K. (2016). Design and implementation of microcontroller based controller for direction and speed of a robot using ARDUINO. 10.13140/RG.2.2.22462.69447.

Kobes, M. (2017). Fire safety of fire safe cigarettes. Fire Service Academy (2017). 17-19.

Kodur, V., Kumar, P. \& Rafi, M. (2019). Fire hazard in buildings: review, assessment and strategies for improving fire safety. 4 (1). 5-11.

Lambert, K. (2013). Extinguishment mechanisms. Compartment Fire Behaviour Training Belgium.

Lyman, D. (2018). Ambulatory Surgery Center Safety Guidebook. Managing Code Requirements for Fire and Life Safety, Butterworth-Heinemaan. 51-56.

Moinuddin, K., Bruck, D., \& Shi, L. (2017). An experimental study on timely activation of smoke alarms and their effective notification in typical residential buildings. Fire Safety Journal. 93, 1-11.

Muhamading, M. (2016). About 6,000 premises destroyed by fire annually in Malaysia. New Straits Time, 28 September 2016. [Online]. Available: https://www.nst.com.my/news/2016/09/176607/about-6000-premises-destroyedfire-annually-malaysia. [Accessed 1 May 2020].

NEMA. (2017), Guide for Proper Use of System Smoke Detectors, Arlington: National Electrical Manufacturers Association.

Prasojo, I., Nguyen, Phong, T. N., Omar, T., \& Shahu, N. (2020). Design of Ultrasonic Sensor and Ultraviolet Sensor Implemented on a Fire Fighter Robot Using AT89S52. Journal of Robotics and Control. 1, 2. 59-63.

Pyne, S. J. (2016). Fire in the mind: changing understandings of fire in Western civilization, Philosophical Transactions. 1-3. 
Ramsay, J. D., \& Kiltz, L. (2018). Critical Issues in Homeland Security: A Casebook, New York: Routledge.

Tsoumis, G. T. (1991). Science and Technology of Wood, Greece: Verlag Kessel.

Wang, Y., Marsden, J., \& Kelly, M. (2011). Challenges of Fire Fighting in Fire Engineered Built Environment. Procedia Engineering, 11, 583-592.

Warmack, R., Wise, M., \& Wolf, D. (2012). Home Smoke Alarms, A Technology Roadmap, 22.

Woodrow, B. (2010). Fire as Vulnerability - The Changing Face of World Fire Statistics. World Fire Statistics 26, 3-4.

Wrack, M. (2010). Why emergency response times matter to firefighters and the public. The Fire Brigades Union, United Kingdom.

Xin, C., Qiao, D., Hong-jie, S., Chun-he, L., \& Hai-kuan, Z. (2018). Design and Implementation of Debris Search and Rescue Robot System Based on Internet of Things. IEEE, Changsha, China. 